\title{
Empirical Study on the Effect of Servant Leadership on Employee Performance: The Mediating Effect of Employee Needs
}

\author{
Mengmeng LI, Fengxia WANG, Daoli WANG \\ Harbin University of Commerce, Harbin, China
}

\begin{abstract}
Leadership behavior is an important factor affecting employees' performance. This research takes employees in a certain household appliance retailer as research subjects, and the employee's needs as mediated variable. This paper makes an empirical analysis on the paths and mechanisms in which servant leadership affects employee performance. On the basis of reading numerous literature, this paper proposes 10 research hypotheses. By designing and issuing research questionnaires, collecting relevant data, utilizing the SPSS17.0 to take on the reliability and validity analysis, correlation analysis, regression analysis, etc., these 10 hypotheses are testified, which gives a further explanation of the influential mechanism among the servant leadership, employees' needs and employee performance. This helps to strengthen the servant leadership, fulfill employees' real need and provide management suggestions for the improvement of employee performance.
\end{abstract}

KEYWORD: Servant leadership; Employees' needs; Employee performance

\section{INTRODUCTION}

Internet era is the era of customer-led businesses, better customer experience has become a source of competitive advantage, the key to business success is the service level of the frontline staff. Status and role of front-line staff have changed greatly. Its dominant position has become obvious increasingly. The defects of traditional authoritarian leadership style is becoming apparent. "2013 American workplace status" report that released by Gallup shows: Today's workplace, only $30 \%$ employees work with a positive attitude, the remaining $50 \%$ of employees are not in the state, $20 \%$ of employees express dissatisfaction by working inefficiently. Gallup believes that bad leadership is the main reason. Therefore, the traditional style of leadership must transform. And what kind of leadership it should become? In practice, Haier gives the answer. It imply the win-win model of human single one, subverts the organizational structure from the "Triangle" to "inverted triangle", improves the status of front-line employees. Employee is at the top, finds and creates needs; leader is at the bottom, serve the staff and meet the needs of employees. This management model just subvert the traditional topdown leadership and produce good results. W. Chan Kim Renee Mauborgne, the authors of the Blue Ocean Strategy, migrate the concept of Blue Ocean to the new field "leadership" in May 2014.They also regard the leadership as a "service", but the staff within the organization may choose to "buy" or "not buy." When subordinates agree with leaders' behavior, they will buy the service. It reflects the employee-focused thought exactly. The leader should focus the needs of staff when he provides the services so that employees can produce good performance.

According to Blue Ocean Leadership theory, I think servant leadership behavior should be expressed that a leader understand and tap the needs of employees consciously. And once the staff put forward the need, the leader should meet actively. This research takes employees in a certain household appliance retailer as research subjects, and the employee's needs as mediated variable. This paper makes an empirical analysis on the paths and mechanisms in which servant leadership affects employee performance. There is also a further explanation on the influencing mechanisms among the servant leadership, employees' needs, and the employee performance.

\section{THEORETICAL MODEL AND RESEARCH HYPOTHESES}

\subsection{Servant Leadership and Employee Performance}

Servant leadership shows a true leader is a "servant". Leader services for the staff, therefore employee 
services customer in the same way that leader services employee. Leader encourages employees to do their best and create good performance continuously. Servant leaders put the interests of subordinates above themselves', respect and develop subordinates, stimulate the potential, guide them self-motivation and self-leadership, to obtain exceptional job performance. Servant leaders put the interests of subordinates above themselves', respect and develop subordinates, stimulate the potential, guide them self-motivation and self-leadership, to obtain exceptional job performance.[1]

Liden(2008) believed that servant leadership could improve organizational commitment, community citizenship behavior and job performance. Neubert (2008) also believed servant leadership can improve the subordinate's helping behavior and innovative behavior.[2] Through the statistical analysis of 285 valid questionnaires paired, Sun Jianmin and Wang Biying (2010) showed that servant leadership is positively related to task performance. [3]Wang Boyi and Gu Qinxuan (2012) suggested that servant leadership can improve employee job satisfaction, organizational commitment, job performance and trust in the leadership, reduce staff burnout, so as to bring greater organizational effectiveness.[4] On the basis of Dennis and Winston's servant leadership dimensions constitution research, Fan Yanran (2012) did the further research in non-profit organizations and considered its three dimensions effect on the volunteer work positively. Liu Xiaomeng(2013) also verified this view. It has been agreed at home and abroad that service leadership has positive impacts on job satisfaction and performance.

Thus, this study presents the following assumptions:

H1: There is a significant positive correlation between servant leadership behavior and employee performance.

H1a: There is a significant positive correlation between servant leadership behaviors and task performance.

$\mathrm{H} 1 \mathrm{~b}$ : There is a significant positive correlation between servant leadership behaviors and contextual performance.

\subsection{Servant Leadership and Employees' Need}

Servant leadership should be used to meet the needs of employees, help employees achieve work goals. If it doesn't achieve such effect, such leadership can not be called servant leadership.

Barbuto\&Wheeler(2006),Washington(2006)consi der that the biggest difference between servant leadership and other leadership style is that it is employee-centric leadership, therefore it greatly enhance employees' job satisfaction. Barbuto \& Wheeler(2006), Weiku Wu(2009), Cerit(2009) also showed that servant leadership and employee satisfaction is significantly positively correlated. He Shankan(2013) believes that servant leadership should deep understand and meet the emotional needs, make "emotional investment". Thus, this study presents the following assumption:

$\mathrm{H} 2$ : There is a significant positive correlation between servant leadership and meeting the employees' needs.

\subsection{Employees' Needs and Employee Performance}

Li Cuiping(2011) generalized that if staffs' needs has been meet or exceeded expectations, they would be satisfied and loyal to the enterprise. Loyal employees work with full enthusiasm and energy. It's easy to drive to other employees to build the corporate identity and the sense of belonging, which will not only save a lot of corporate human resources management and development costs, but also help enhance the company's production efficiency and corporate image.

Deng Zhihua(2012) took the job satisfaction as mediating variable and researched the effects of servant leadership to employee behavior. He showed that servant leadership could promote organizational citizenship behavior of employees, reduce workplace deviate conduct. So it would promote enterprise development.

He Yueping (2013) did the empirical analysis of the relationship among the demand for employees, job stress and loyalty .The result showed employees' needs is positive correlated of organizational loyalty.

Based on the theory of employee needs, Yang Yelin (2014) studied the incentive mechanism for small and medium enterprises .He believed that if the incentive meet the staffs' needs, it would play a multiplier role in mediating the staff motivation.

Thus, this study presents the following assumptions:

H3: There is a significant positive correlation between employees' needs and employee performance.

H3a: There is a significant positive correlation between employees' needs and task performance.

$\mathrm{H} 3 \mathrm{~b}$ : There is a significant positive correlation between employees' needs and contextual performance.

\subsection{Mediating Role of Employees' needs}

Mayer(2008) found servant leadership could establish the organizational justice and meet the employees' needs, thereby it motivate employees to work better.[5]Luo Ming(2008) thought servant leadership make efforts to meet the employees' needs under the spirit of serving and helping, creating organizational success. Yan Han(2013) proposed that under the servant leadership, the member can 
get service from leaders, and their own needs can be well satisfied, therefore, they trust the organization and leaders. Thus, this study presents the following assumptions:

H4: employees needs play an intermediary role between the servant leadership and employee performance.

H4a: employees needs play an intermediary role between the servant leadership and task performance.

$\mathrm{H} 4 \mathrm{~b}$ : employees needs play an intermediary role between the servant leadership and contextual performance.

This research takes the employee's needs as mediated variable and makes an empirical analysis on the paths and mechanisms in which servant leadership affects employee performance. The author builds the theoretical model as Figure 1.

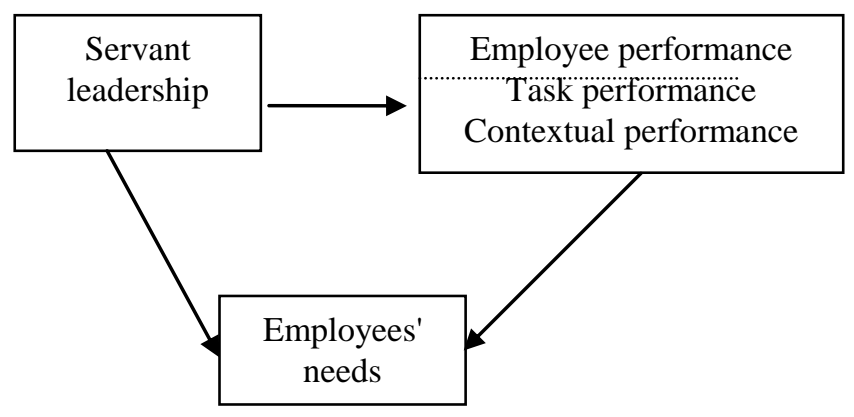

Figure 1. Theoretical model

\section{DATA MEASUREEMENT AND HYPOTHESIS VERIFICATION}

\subsection{Questionnaire design}

The questionnaire consists of two parts. The first part is questionnaire for basic information, and the second part is questionnaire for variable measurement. The second part is constituted of three scales, which are selected from mature scales of high reliability and validity. These three scales are for items of servant leadership, staff need, and staff performance. The specific measurement adopts 5 points Likert scale; 1 for completely disgree; 2 for not too disagree, 3 for ordinary; 4 for partly agree; 5 for completely agree. The higher of the mark, the higher degree of agreement; the lower of the mark, the lower degree of agreement.

This research use Ehrhat (2004) Scale for servant leadership, including 10 items asked; use Van Scotter \& Motowidlo(1994) Scale for employee performance, including 10 items. According to Maslow's hierarchy of needs, Alcatel Devils ERG theory, as well as 《critical moment - MOT》 described by Zhan - Carlson, this research refines seven dimensions about employees needs. The main needs are vision needs, power needs, resource needs, strategy needs, interpersonal needs, emotional needs. The author design 10 items around these seven dimensions.

\subsection{Questionnaires issue}

Questionnaires were issued from April 2014 to the end of July. Due to the limitation of human 、 financial and time, the author is unable to carry out a nationwide survey, the selected samples are majorly from employees who work in household appliance retailer. Therefore, to ensure the feasibility of the case, so that the conclusion has certain limitations. A total of 200 questionnaires are distributed, 178 valid questionnaires are recovered at last.

\subsection{Reliability and validity analysis of questionnaire}

This paper use Cronbach's $\alpha$ coefficient to test reliability of scales, the higher of the coefficient, the more stable and reliable of the test. As shown in Table 1, the reliability of each project is more than 0.8 , indicating the scale has higher internal consistency.

Table 1 Reliability analysis

\begin{tabular}{|c|c|c|c|}
\hline scales & dimensions & items & Cronbach's $\alpha$ \\
\hline Servant leadership & $/$ & 10 & 0.936 \\
\hline Employees' needs & $/$ & 10 & 0.868 \\
\hline Employee performance & Task performance & 3 & 0.883 \\
\hline Total & Contextual performance & 7 & 0.897 \\
\hline
\end{tabular}

The scales used in this study are selected from the classic literatures, most of the questionnaires are widely used by domestic and foreign scholars. Based on valid questionnaires, this study do the factor analysis, thus to prove the construct validity of the questionnaire. We need to test KMO and Bartlett to judge whether has correlations between the variables before doing the factor analysis. If the KMO value is greater than 0.7 , it's suitable for factor analysis. The greater of the value, the greater degree of influence on the current variable factor. In this study, these there questionnaires' KMO are above 0.8 , indicating 
that these scales are suitable for factor analysis and the questionnaires have high validity.

\subsection{Correlation analysis}

This paper uses Spss17.0 to carry out correlation analysis among servant leadership, employees' needs and employee performance. The specific results are shown in Table 2. It can clearly be seen, between the variables has significant positive correlation. It's suitable to do the regression analysis.

Table 2 Results of correlation analysis

\begin{tabular}{|c|c|c|c|c|c|}
\hline dimensions & $\begin{array}{c}\text { Servant } \\
\text { leadership }\end{array}$ & $\begin{array}{c}\text { Employees' } \\
\text { needs }\end{array}$ & $\begin{array}{c}\text { Employee } \\
\text { performance }\end{array}$ & $\begin{array}{c}\text { Task } \\
\text { performance }\end{array}$ & $\begin{array}{c}\text { Contextual } \\
\text { performance }\end{array}$ \\
\hline \multicolumn{6}{|l|}{ Servant leadership } \\
\hline Employees' needs & $0.412 * *$ & & & & \\
\hline Employee performance & $0.373^{* *}$ & $0.398 * *$ & & & \\
\hline Task performance & $0.224 * *$ & $0.347 * *$ & $0.517 * *$ & & \\
\hline Contextual performance & $0.305 * *$ & $0.409 *$ & $0.470 * *$ & $0.312 *$ & \\
\hline
\end{tabular}

\subsection{Regression analysis}

This paper makes further predictions on the relationship between the three variables by using SPSS17.0. Results of the regression analysis are shown in Table 3, There are significant positive correlation between the variables. The hypothesis H1, H1a, H1b, H2, H3, H3a, H3b are all set up.

Table 3 Results of the regression analysis

\begin{tabular}{|l|l|c|c|c|c|c|}
\hline Independent variable & Dependent variable & $\beta$ & $\mathrm{t}$ & $\mathrm{Sig}$ & Adj. $\mathrm{R}^{2}$ & $\mathrm{~F}$ \\
\hline Servant leadership & Employee performance & 0.389 & 4.937 & .000 & .092 & $29.265^{* * *}$ \\
\hline Servant leadership & Task performance & 0.404 & 5.239 & .000 & .087 & $35.427^{* * *}$ \\
\hline Servant leadership & Contextual performance & 0.237 & 3.891 & .000 & .059 & $11.393^{* *}$ \\
\hline Servant leadership & Employees' needs & 0.513 & 7.136 & .000 & .585 & $42.179^{* * *}$ \\
\hline Employees' needs & Employee performance & .337 & 6.275 & .000 & .293 & $39.837^{* * *}$ \\
\hline Employees' needs & Task performance & .384 & 6.931 & .000 & .311 & $41.272^{* * *}$ \\
\hline Employees' needs & Contextual performance & .320 & 6.014 & .000 & .243 & $37.683^{* * *}$ \\
\hline
\end{tabular}

Now we need to analyze the intermediary role of employee's needs between the servant leadership behavior and employee performance. This paper adopts the intermediary test method that proposed by Baron \& Kenny (1986).

When introducing "Employees need" as a mediating variable, the regression coefficient between the three variables are significant level, and regression coefficient that "servant leadership " acts on the "Employee Performance" is from 0.389 down to 0.372 , regression coefficient that acts on the "task Performance "is from 0.404 down to 0.365 , regression coefficient that acts on the" contextual performance "is from 0.237 down to 0.182 . Just to meet the four conditions that proposed by Baron \& Kenny. Thus, all three assumptions, H4, H4a, H4b, are set up.

\section{RESEARCH RESULT AND SUGGESTIONS FOR MANAGEMENT}

\subsection{Research result}

Through relevant analysis, it can be concluded that there is a promident relation among the service leadership, employees' need and employees' performance. Through regression analysis, it can be found that employees' need plays a mediation role in the service leadership, employee performance and the dimension between them. These results testify ten hypotheses in this paper.

The service leadership has a positive correlation with the employee performance and its dimensions. It means that leadership relations can effectively improve the levle of employees' performance. Service leadership can not only directly affect employees' performance and its dimension, but also has its indirect impact through the fulfillment of the employees' need. The excavation of the employees' need and its fulfillment plays the mediation role 
between the service leadership and the employees' performance.

\subsection{Suggestions for Management}

\subsubsection{Employing the Blue Ocean Leadership to Perfect Service Leadership}

The traditional methods of improving the leadership mostly focus on the suppliers, which stress that the what the leaders should be. They mainly consider factors such as values, quality, personality, etc. This change of the internal though is very long and it goes far away from the organization reality and the performance goal.

How to change the leadership on the condition of getting fast and time-saving? W. Chan Kim \& Renee Mauborgne gave an effective solution of Blue Ocean Leadership on May 6th 2014 to this question. It has been specifically explained that four steps can put the Blue Ocean Leadership into practice: understanding the status quo of current leadership, depicting ideal portrait of leadership, choosing ideal protrait of leadership, and regularizing the ideal leadership. Leaders no longer need to change the personality or break old rules. They just need to change their behavior in order to complete the change of the leadership in a short time, which gives a beneficial implication for leaders to realize their service leadership.

\subsubsection{Fully Considering Employees' Need}

Service leaders should take employees as the center and fully consider the employees' need. What the leaders do should be decided by employees. Leaders ought to understand and extracate employees' need consciously. Once employees put forward their needs, the leader should provide service to his best.

As is stressed by Zhan - Carlson in 《critical moment $\bullet$ MOT $\rangle$, the real leaders should regularly depict to the employees the golrious vision of future of the company with concise language expressions, which can keep employees with clear and positive striving goal. The leaders should also entrust employees with the right of making decisions for themselves, which can fulfill the employees' need of future vision and the need of making decisions for themselves.

\section{ACKNOWLEDGEMENTS}

1. A Research on the Breakthrough of Management Mode in Growing SMEs-A Case Study of SMEs in Heilongjiang Province (YJSCX2013-258HSD)

2. Natural Science Foundation of Heilongjiang Province: Large-scale private enterprises' management bottlenecks and their breakthrough, Heilongjiang enterprises as examples (G201318)

3. Social science planning projects in Heilongjiang Province: Labor brand building in the process of the transformation of economic development patterns (13D026)

\section{REFERENCES}

[1] Peng Zhaoqi. The relationship between servant leadership and organizational citizenship behavior: effects and moderating effects. Zhejiang Sci-Tech University, 2013.

[2] Huang Haiyan. On the impact of servant leadership style, job satisfaction on innovative behaviors of R\&D teams. Contemporary Economy \& Management, 2013, 10:79 83.

[3] Sun Jianmin, Wang Biying. Servant Leadership: Scale Development and Construct Clarification. Journal of business economics, 2010, 5: 24 29.

[4] Wang Boyi, Gu Qinyi. The inspiration and review on constructs, influencing factors and the structure of servant leadership. Modern Management Science, 2012,11:12 14.

[5] Zhang Qiongyue. An empirical study of the relationship between employee turnover and service leadership, organizational commitment. He Bei University, 2014. 